\title{
Biogenic silver nanoparticles using Rhinacanthus nasutus leaf extract: synthesis, spectral analysis, and antimicrobial studies
}

This article was published in the following Dove Press journal:

International Journal of Nanomedicine

30 August 2013

Number of times this article has been viewed

\author{
Visweswara Rao Pasupuleti \\ TNVKV Prasad ${ }^{2}$ \\ Rayees Ahmad Shiekh ${ }^{3}$ \\ Satheesh Krishna Balam ${ }^{4}$ \\ Ganapathi Narasimhulu ${ }^{5}$ \\ Cirandur Suresh Reddy ${ }^{4}$ \\ Ismail Ab Rahman ${ }^{3}$ \\ Siew Hua Gan' \\ 'Human Genome Center, School \\ of Medical Sciences, Universiti Sains \\ Malaysia, Kubang Kerian, Kelantan, \\ Malaysia; ${ }^{2}$ Institute of Frontier \\ Technology, Regional Agricultural \\ Research Station, Acharya NG Ranga \\ Agricultural University, Tirupati, \\ Andhra Pradesh, India; ${ }^{3}$ Biomaterial \\ Research Unit, School of Dental \\ Sciences, Universiti Sains Malaysia, \\ Kubang Kerian, Kelantan, Malaysia; \\ ${ }^{4}$ Department of Chemistry, Sri \\ Venkateswara University, Tirupati, \\ Andhra Pradesh, India; ${ }^{5}$ Pharmacology \\ and Toxicology, Faculty of Pharmacy, \\ University of Technology Mara, \\ Malaysia
}

\begin{abstract}
Nanotechnology is gaining momentum due to its ability to transform metals into nanoparticles. The synthesis, characterization, and applications of biologically synthesized nanomaterials have become an important branch of nanotechnology. Plant extracts are a cost-effective, ecologically friendly, and efficient alternative for the large-scale synthesis of nanoparticles. In this study, silver nanoparticles (AgNps) were synthesized using Rhinacanthus nasutus leaf extract. After exposing the silver ions to the leaf extract, the rapid reduction of silver ions led to the formation of AgNps in solution. The synthesis was confirmed by ultraviolet-visible spectroscopy, Fourier transform infrared spectroscopy, and transmission electron microscopy. The in vitro antimicrobial activity of the AgNps synthesized using $R$. nasutus leaf extract was investigated against Bacillus subtilis, Staphylococcus aureus, Pseudomonas aeruginosa, Klebsiella pneumonia, Escherichia coli, Aspergillus niger, and Aspergillus flavus using a disc diffusion method. The AgNps showed potential activity against all of the bacterial strains and fungal colonies, indicating that $R$. nasutus has the potential to be used in the development of value-added products in the biomedical and nanotechnology-based industries.
\end{abstract}

Keywords: $R$. nasutus, silver nanoparticles, TEM, antimicrobial activities

\section{Introduction}

Nanomaterials have extensive applications for improving human health and the environment. The first reported use of nanomaterials for human health was over 5,000 years ago in the Indian system of Ayurveda medicine, in which nanoscience technology was applied before the term "nano" was even coined. ${ }^{1}$ It was only in the 21 st century that modern science initiated nanoscience research, and development in this field has been rapidly growing throughout the world. A major outcome of this research is the development of new materials at the nanometer scale, including the development of nanoparticles.

Nanoparticles are particulate materials that consist of at least one dimension that is less than 100 nanometers (nm). In the case of quantum dots, nanoparticles can even consist of zero dimensions. Due to their small size, surface (interface), and quanta tunnel effects, nanomaterials have different characteristics compared to non-nanomaterials composed of similar components. With the development of novel chemical and physical production methods, there is the increasing concern of environmental contamination due to the large amounts of hazardous by-products often generated by the chemical procedures utilized for the synthesis of nanomaterials. There is a strong need for "green methods," methods that are clean, nontoxic, and environmentally friendly, for the synthesis of nanoparticles. ${ }^{2}$ 
Metal nanoparticles have a high specific surface area and a small fraction of surface atoms. They have been extensively studied due to their unique physicochemical characteristics, which include improved optical, electronic, antibacterial, and magnetic properties, as well as their catalytic activities. ${ }^{3}$ The synthesis of noble nanoparticles for electronics and environmental and biotechnology applications is an area of continued interest. ${ }^{4}$ In general, metal nanoparticles are synthesized and stabilized using chemical methods such as chemical reduction, ${ }^{5,6}$ electrochemical techniques, ${ }^{7}$ and microwave-assisted process, ${ }^{8}$ while more recent methods utilize green technology. ${ }^{9}$ The use of plants for the synthesis of nanoparticles is novel and provides a cost-effective and environmentally friendly alternative to chemical and physical synthesis. In addition, the use of plants can be easily scaled up for large-scale synthesis without the use of toxic chemicals or the need for high pressures, energy, and temperatures.

Although both bacteria and fungi can be used for the synthesis of nanoparticles, ${ }^{10,11}$ the use of leaf extract ${ }^{12}$ is inexpensive and eliminates the requirement for special culture preparations and isolation techniques. Plants may play a major role in the synthesis of nanoparticles because their use would eliminate the formation of toxic by-products formed during the synthesis process. ${ }^{13}$ In recent years, the biosynthesis of nanoparticles using plant extracts has achieved much attention when compared to physical and chemical methods, with even higher attention received when compared to using microbes since maintaining aseptic conditions are not required ${ }^{14}$ Furthermore, all plant parts such as the leaves, stems, seeds, roots, and fruits can be used in the synthesis, replacing the need to use potentially hazardous chemicals such as sodium borohydride $\left(\mathrm{NaBH}_{4}\right) \cdot{ }^{15}$ Nanoparticles are usually prepared from plant extracts since they can act not only as reducing agents but also as capping agents. ${ }^{16,17}$ Silver (Ag) has long been recognized for its inhibitory effect on microbes that may be present in medical and industrial processes. ${ }^{18,19} \mathrm{Ag}$ nanoparticles (AgNps) may be used in more applications compared to other metal nanoparticles, including nonlinear optics, spectrally selective coating for solar energy absorption, biolabeling, intercalation materials as optical receptors for electrical batteries, antibacterial agents, and catalysts in chemical reactions. ${ }^{20}$ The most important application of $\mathrm{Ag}$ and $\mathrm{AgNps}$ in the medical industry is their use in topical ointments that prevent infections in burns and open wounds. ${ }^{21}$ Jayaseelan reported the activity of synthesized AgNps against Hippobosca maculata larvae by using an aqueous leaf extract of Musa paradisiaca. ${ }^{22}$ Other recent reports include the efficacies of anti-parasitic activities of
AgNps using the aqueous extract of Cissus quadrangularis stem against the adult hematophagous fly $H$. maculata (Diptera: Hippoboscidae) and the larvae of the cattle tick, Rhipicephalus (Boophilus) microplus (Acari: Ixodidae). ${ }^{23,24}$ Earlier reports on AgNps include its properties as potential antifungal, ${ }^{25}$ antibacterial, ${ }^{26}$ and antiviral activities. ${ }^{27}$ In this scenario, we have selected Rhinacanthus nasutus leaf extract for this study to prepare the AgNps and test the antimicrobial activities.

$R$. nasutus, commonly known as snake jasmine, is an erect, small-branched shrub from the Acanthaceae family. It is a medicinal plant found in some regions of India, the People's Republic of China, and in areas of Southeast Asia including Thailand. ${ }^{28}$ Traditional medicinal preparations from the roots, stems, and leaves of this shrub have long been used in Thai traditional medicine for the treatment of various diseases.$^{29}$ Previously, we reported that $R$. nasutus exhibits potential antimicrobial properties and can kill a variety of infecting organisms, in addition to revealed anti-diabetic effects, amelioration of mitochondrial and cytosolic enzymes, ${ }^{30}$ hypolipidemic activity, ${ }^{31}$ and significant in vitro and in vivo antioxidant activities. ${ }^{32}$

We report for the first time, the synthesis and characterization of $\mathrm{AgNps}$ generated by the reduction of R. nasutus aqueous leaf extract. The biologically synthesized nanoparticles were analyzed and tested against several different pathogenic microorganisms.

\section{Material and methods Collection of the plant material}

Fresh $R$. nasutus (Linn.) leaves (500 g) were collected from Seshachala Hills, Tirumala and Andhra Pradesh. They were authenticated by a botanist, Dr Madhava Chetty, from the Botany department, Sri Venkateswara University, Tirupati and Andhra Pradesh.

\section{Preparation of the plant extract and $\mathrm{AgNps}$}

Dried leaf powder $(10 \mathrm{~g})$ was mixed with $100 \mathrm{~mL}$ of deionized water in an Erlenmeyer flask (500 mL) - 4060024 (Borosil Glass Works Ltd., Thadani Marg, Worli, Mumbai, India), and was boiled for 20 minutes. For the reduction of $\mathrm{Ag}$ ions $\left(\mathrm{Ag}^{+}\right)$, 5,10 , and $15 \mathrm{~mL}$ of the aqueous leaf extract were carefully added to $90 \mathrm{~mL}$ of $1 \mathrm{mM}$ aqueous $\mathrm{Ag}$ nitrate and chloroauric acid solution in $250 \mathrm{~mL}$ flasks. For this process, the aqueous leaf extract of $R$. nasutus was used.

For the synthesis of AgNps using R. nasutus, 5, 10, and $15 \mathrm{~mL}$ of the aqueous leaf extract were carefully added to $90 \mathrm{~mL}$ of $1 \mathrm{mM}$ aqueous $\mathrm{Ag}$ nitrate and chloroauric acid 
solution in $250 \mathrm{~mL}$ flasks. The mixture was then heated for 20 minutes at a temperature ranging between $60^{\circ} \mathrm{C}$ and $80^{\circ} \mathrm{C}$. The color of the solution changes from brown to red to confirm the synthesis of AgNps.

\section{Fourier transform infrared spectroscopy (FTIR) and ultraviolet-visible (UV-Vis) spectral analysis of $\mathrm{AgNps}$}

To remove compounds that did not function as the capping ligand of the nanoparticles as well as any unbound biomass residue, the residual solution $(100 \mathrm{~mL})$ was centrifuged at $5,000 \mathrm{rpm}$ for 10 minutes, and the supernatant was resuspended in $10 \mathrm{~mL}$ of sterile distilled water. The centrifugation and resuspension process was repeated three times. The purified suspension was then freeze dried to obtain the dried powder, and the dried nanoparticles were analyzed using FTIR (Tensor 37; Bruker Optik GmbH, Ettlingen, Germany).

The reduction of the pure $\mathrm{Ag}^{+}$ions was monitored by measuring the UV-Vis spectrum of the reaction medium at 5 hours following the dilution of a small aliquot of the sample in distilled water. The UV-Vis spectral analysis was conducted using a UV-Vis spectrophotometer between 200 and $800 \mathrm{~nm}$ (Cary 4000 UV-Vis spectrophotometer; Agilent Technologies, Santa Clara, CA, USA) with specific monitoring at $437 \mathrm{~nm}$.

\section{Transmission electron microscopy (TEM)}

TEM (H-7500; Hitachi Ltd, Tokyo, Japan) is a microscopy technique in which a beam of electrons is transmitted through an ultra-thin specimen. The ultra-thin film was prepared on a carbon-coated copper grid by placing a small amount of $R$. nasutus nanoparticles on the grid and then drying the particles under a lamp. An image is formed as a result of the interaction of the transmitted electrons with the specimen.

\section{Particle size and zeta potential measurement - dynamic light scattering (DLS)}

Particle size distribution was studied using a DLS technique (Nanopartica SZ-100; HORIBA Ltd, Kyoto, Japan). The scattered light from the particles present in the sample was collected either at 90 or 173 degrees, which was automatically selected by the instrument as the optimum scattering angle based on sample concentration. The zeta potential, which is an indicator of dispersion and stability of the prepared nanoparticles was also measured.

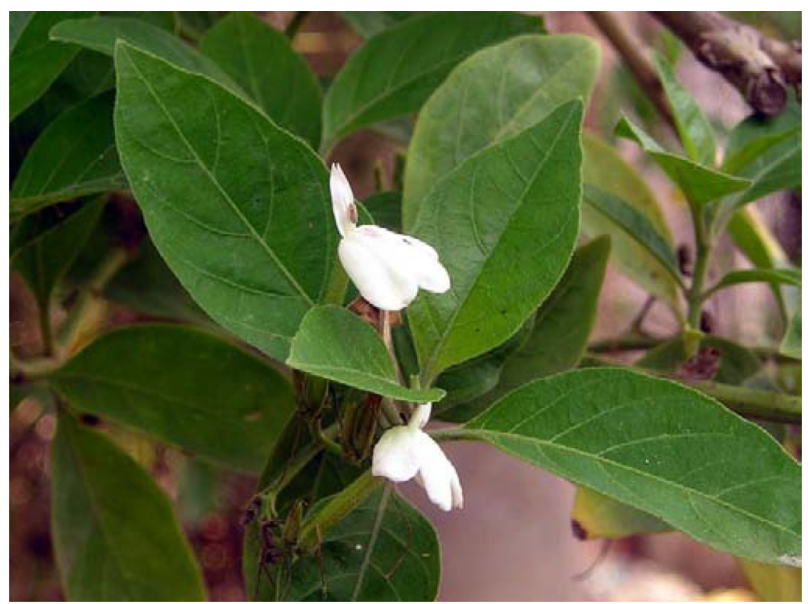

Figure I Photograph of Rhinacanthus nasutus leaf.

\section{X-ray diffraction (XRD) analysis of AgNps}

The silver nanoparticle solution obtained above was purified by conducting repeated centrifugation at 5,000 rpm for 20 minutes followed by redispersion of $\mathrm{AgNps}$ pellet into $10 \mathrm{~mL}$ of deionized water. After freeze drying of the purified Ag particles, the structure and composition was analyzed by using an XRD machine (RINT 2100 series; Rigaku Corporation, Tokyo, Japan). The dried mixture of AgNps was collected for the determination of the formation of AgNps by an X'Pert Pro X-ray diffractometer (PANalytical BV, Almelo, The Netherlands) operating at a voltage of $40 \mathrm{kV}$ and a running current of $30 \mathrm{~mA}$ with $\mathrm{Cu} \mathrm{K} \alpha$ radiation in a $\theta-2 \theta$ configuration.

\section{Antibacterial activity}

The antimicrobial activity of $R$. nasutus and the AgNps prepared from $R$. nasutus was evaluated using the disc diffusion method. Ciprofloxacin (10 $\mu \mathrm{g} /$ disc) was used as a standard for comparison. Filter paper discs were soaked in the extract $(50 \mu \mathrm{g} / \mathrm{mL})$, and the ciprofloxacin discs were aseptically placed on seeded agar medium (Hi-Media Laboratories Pvt Ltd, Mumbai, India).

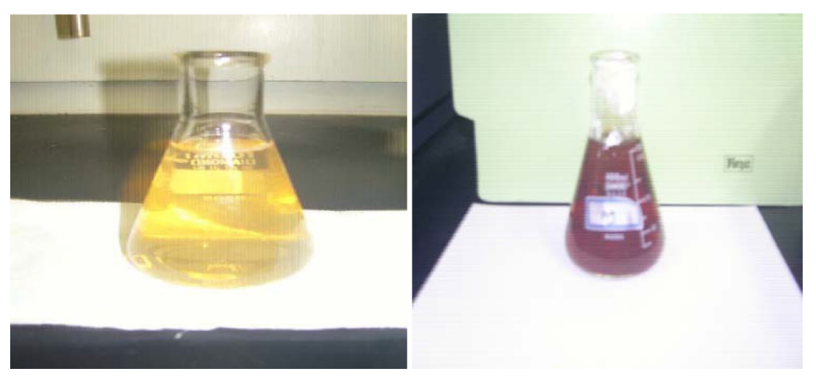

Figure 2 Color change of Rhinacanthus nasutus leaf extract containing silver before (left) and after (right) synthesis of silver nanoparticles. 


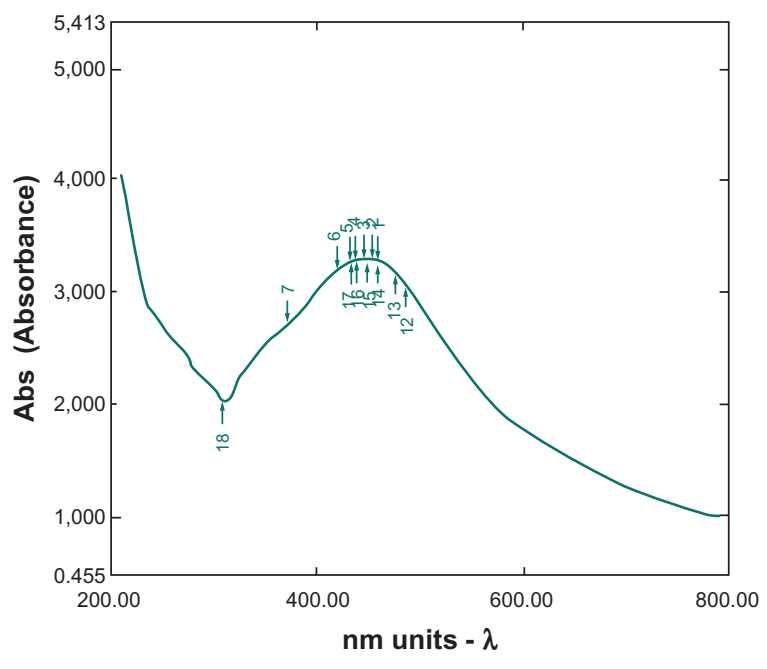

Figure 3 Ultraviolet-visible spectra of the silver nanoparticles synthesized from Rhinacanthus nasutus leaf extract.

The medium was incubated with the test organisms at $37^{\circ} \mathrm{C}$ for 24 hours, ${ }^{33}$ and the antimicrobial activity was assessed based on the inhibition zones formed around the discs by the plant extracts compared to the zones around the ciprofloxacin.

\section{Antifungal activity}

The antifungal activity of $R$. nasutus and the AgNps prepared from $R$. nasutus was determined against Aspergillus niger and Aspergillus flavus using the disc diffusion method. Prior to the experiment, the filter paper discs were individually saturated with the extracts $(50 \mu \mathrm{g} / \mathrm{mL})$ and then aseptically placed on Sabouraud Dextrose Agar - M063 (Himedia Laboratories, L.B.S. Marg, Mumbai, India), medium that had been incubated with the culture. The plates were then incubated at $37^{\circ} \mathrm{C}$ for 48 hours ${ }^{33}$ since the incubation time for microbial growth varies between fungi and bacteria. The zone of inhibition was measured (in millimeters), and the means of triplicate samples were recorded.

\section{Statistical analysis}

The results were expressed as the mean \pm standard deviation of triplicates. Statistical analysis was performed using oneway analysis of variance (ANOVA) followed by Tukey's test. $P<0.05$ was considered statistically significant.

\section{Results and discussion}

The development of biologically inspired experimental processes for the synthesis of nanoparticles is evolving into an important branch of nanotechnology. In this study, we successfully synthesized AgNps using $R$. nasutus leaf extract (Figure 1).

\section{UV-Vis spectral analysis of $\mathrm{AgNps}$}

The formation and stability of AgNps in an aqueous colloidal solution was investigated using UV-Vis spectral analysis. As expected, AgNps turned yellowish brown in the aqueous solution, which has been attributed to the excitation of surface plasmon vibrations in AgNps (Figure 2). ${ }^{34,35}$

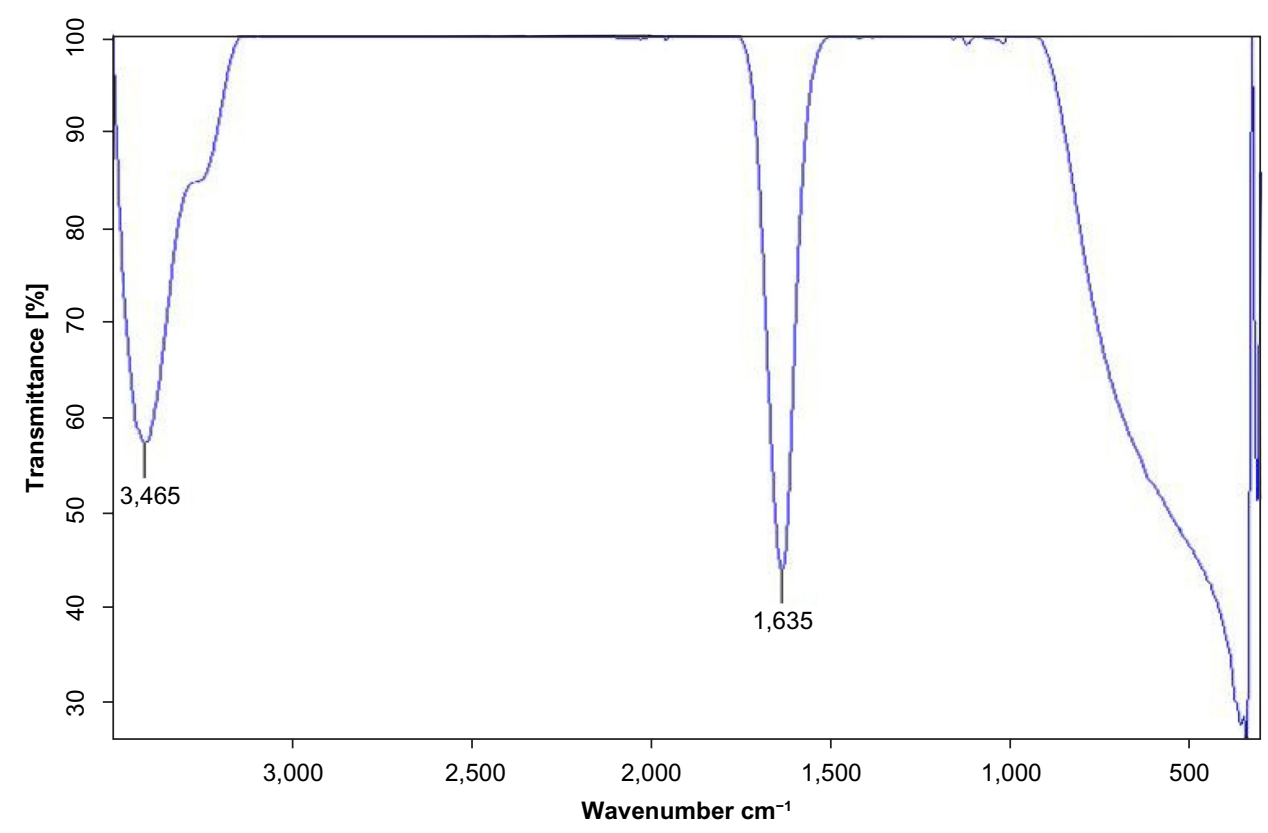

Figure 4 Fourier transform infrared spectroscopy spectra of the silver nanoparticles synthesized from Rhinacanthus nasutus leaf extract after 24 hours. 


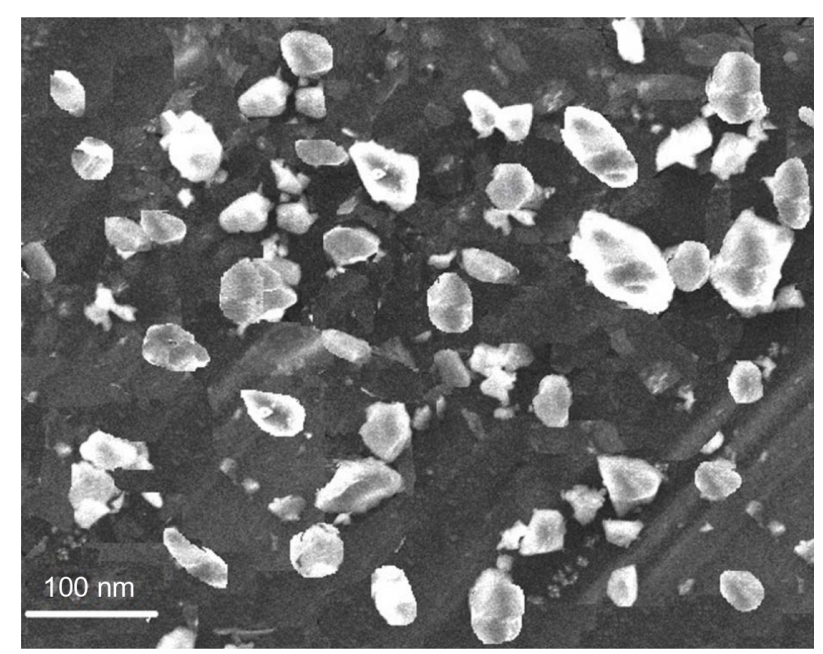

Figure 5 Transmission electron microscopy image of the silver nanoparticles synthesized from Rhinacanthus nasutus leaf extract.

Following the addition of $R$. nasutus leaf extract to the $\mathrm{AgNO}_{3}$ aqueous solution, the color changed from yellow to reddish brown as a result of the reduction of the Ag ions into AgNps.

UV-Vis spectroscopy is utilized to analyze the size and shape of nanoparticles in aqueous suspensions, ${ }^{36}$ and the UVVis spectra was recorded after the solution was heated at $80^{\circ} \mathrm{C}$ for 15 minutes. The absorption spectra of the AgNps had an absorbance peak at $437 \mathrm{~nm}$, and a broadening of the peak indicated that the particles were polydispersed (Figure 3).

\section{FTIR analysis of AgNps}

The FTIR spectra were recorded to identify potential biomolecules that contributed to the reduction of the $\mathrm{Ag}^{+}$ ions and to the capping of the bioreduced AgNps. The FTIR spectrum was recorded 1 day following the formation of the AgNps. A band observed at $1,635 \mathrm{~cm}^{-1}$ may be attributed to the carbonyl groups in the $\alpha$-helices present in the plant extract. The amide I band primarily consisted of the carbonyl $(\mathrm{C}=\mathrm{O})$ stretching of the peptide backbone at $1,635 \mathrm{~cm}^{-1}$. The energy at this vibration is sensitive to the secondary and tertiary structure of the proteins. The band observed at $3,465 \mathrm{~cm}^{-1}$ was characteristic of $-\mathrm{NH}$ stretching of the amide (II) band. Several bands between $2,200 \mathrm{~cm}^{-1}$ to $3,400 \mathrm{~cm}^{-1}$ were absent, which could be attributed to protein precipitation occurring during the reduction and stabilization of the AgNps (Figure 4).

\section{Morphological analysis of the AgNps using TEM}

The applications for AgNps are highly dependent on the chemical composition, shape, size, and monodispersity of the particles. ${ }^{37}$ To broaden the potential scope of applications, the AgNps were characterized using TEM. The samples resulted in a narrow particle size distribution with a mean size for all of the synthesized AgNps of less than $22 \mathrm{~nm}$ and a smaller size $(\sim 11.5 \mathrm{~nm})$ that appeared to be spherical (Figure 5).

\section{Particle size and zeta potential measurement}

The distribution of the particle size and the zeta potential were measured using a Nanopartica SZ-100 (HORIBA Ltd). The mean particle size was $329 \mathrm{~nm}$. It was evident

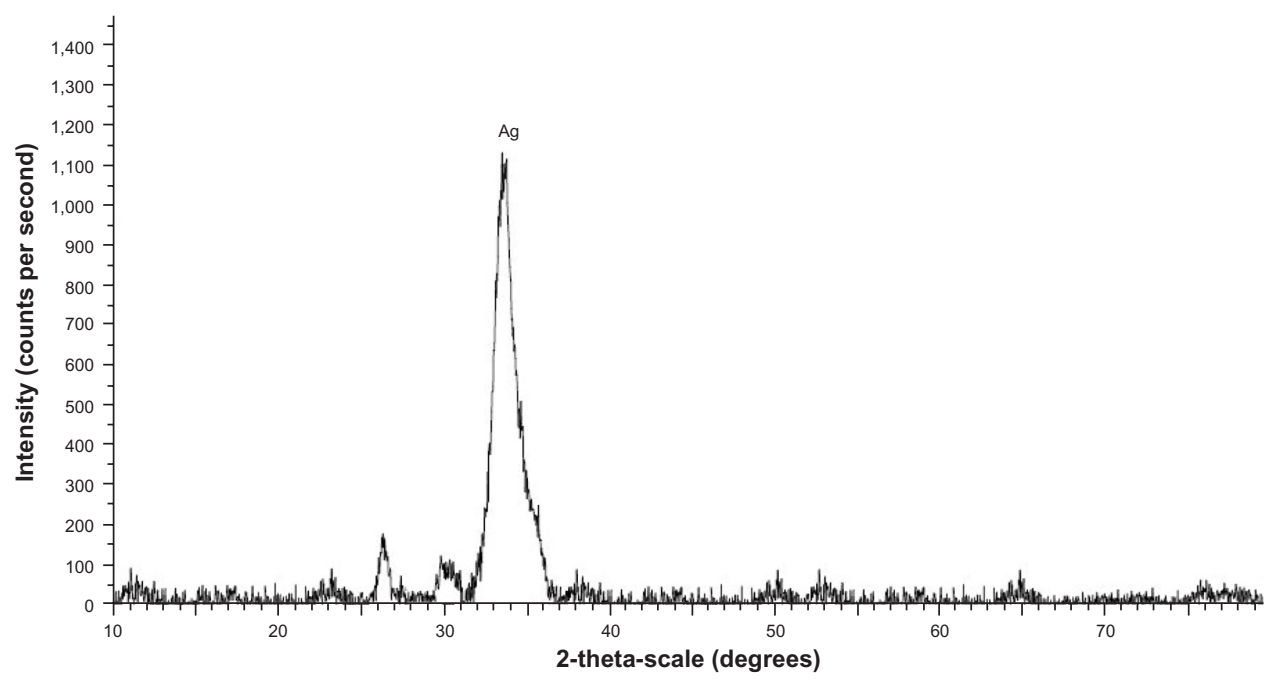

Figure 6 X-ray diffraction pattern of silver nanoparticles synthesized from Rhinacanthus nasutus leaf extract. 
Table I Antimicrobial activity of Rhinacanthus nasutus extract, silver nanoparticles of $R$. nasutus and ciprofloxacin as the zone of inhibition $(\mathrm{mm})$

\begin{tabular}{lclc}
\hline Test organisms & Zone of inhibition $\mathbf{( m m})$ & & Ciprofloxacin \\
\cline { 2 - 4 } & $\begin{array}{l}\boldsymbol{R} \text {. nasutus } \\
\text { extract }\end{array}$ & $\begin{array}{l}\text { Silver nanoparticles } \\
\text { of } \boldsymbol{R} \text {. nasutus extract }\end{array}$ & $18.66 \pm 1.52$ \\
\hline Staphylococcus aureus & $8.33 \pm 0.57$ & $17.66 \pm 0.57$ & $18.33 \pm 1.52$ \\
Bacillus subtilis & $10.33 \pm 0.57$ & $15.66 \pm 1.15$ & $18.66 \pm 1.52$ \\
Pseudomonas aeruginosa & $12.66 \pm 2.51$ & $17.33 \pm 1.52$ & $17.66 \pm 2.51$ \\
Escherichia coli & $11.33 \pm 1.52$ & $17.33 \pm 1.52$ & $19.66 \pm 0.57$ \\
Klebsiella pneumonia & $13.33 \pm 1.52$ & $17.66 \pm 1.52$ & $16.66 \pm 1.52$ \\
Aspergillus niger & $9.66 \pm 2.08$ & $17.66 \pm 1.52$ & $18.66 \pm 0.57$ \\
Aspergillus flavus & $12.66 \pm 2.51$ & $18.66 \pm 1.52$ & \\
\hline
\end{tabular}

from the TEM micrograph that the particles were agglomerated and the size measured by the DLS technique may be the size of the cluster rather than an individual particle. This was further confirmed from the low zeta potential $(-18.1 \mathrm{~V})$.

Data is provided for both the zeta potential and the particle size in Figures S1 and S2.

\section{XRD analysis of AgNps}

The XRD confirmed the presence of Ag colloids in the sample. The Braggs reflections were observed in the XRD pattern at $2 \theta=26.3$ and 30.01. A strong diffraction peak located at 34.50 was ascribed to the (111) facets of Ag. The XRD pattern thus clearly indicated that the AgNps formed in the present synthesis were crystalline in nature. No impurities peaks were observed in the XRD pattern, indicating that the investigated AgNps were pure (Figure 6).

\section{Antimicrobial activity}

In this study, $R$. nasutus leaf extract and the AgNps synthesized with $R$. nasutus leaf extract were tested for their antimicrobial activities against Staphylococcus aureus,
Bacillus subtilis, Pseudomonas aeruginosa, Escherichia coli, Klebsiella pneumonia, and the two fungal cultures $A$. niger and A. flavus. In general, the AgNps potentiated the antimicrobial activity of $R$. nasutus. The antimicrobial activity was performed against several Gram-positive bacteria, Gram-negative bacteria, and fungi also. The data presented in (Table 1) indicate that the AgNPs from $R$. nasutus inhibited the growth of all tested microorganisms to various levels. The AgNPs showed highest activity against the gram positive bacteria $S$. aureus $(17.66 \pm 0.57 \mathrm{~mm})$, gram negative $K$. pneumonia $(17.66 \pm 1.52 \mathrm{~mm})$, as well as against two types of fungi: A. flavus $(18.66 \pm 1.52)$ and A. niger $(17.66 \pm 1.52 \mathrm{~mm})$.

AgNPs are extensively used in the pharmaceutical industry and have inhibitory activities on various microorganisms. They have also been used in balms and ointments to avert infections following burns and wounds..$^{13}$ The maximum inhibitory activity was shown against $A$. flavus, while the lowest activity was observed against the bacteria $B$. subtilis $(15.66 \pm 1.15 \mathrm{~mm})$. When compared to ciprofloxacin, the AgNps showed comparable activities against fungal cultures (Figure 7).
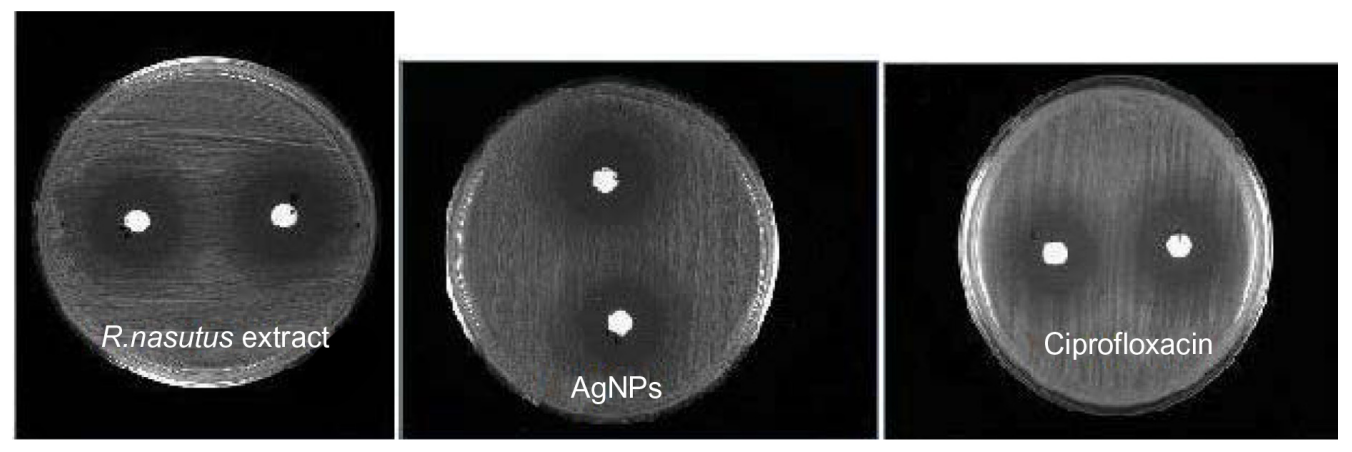

Figure 7 Antibacterial activity of Rhinacanthus nasutus leaf extract (control), silver nanoparticles, and ciprofloxacin against Bacillus subtilis. Abbreviation: AgNPs, silver nanoparticles. 


\section{Conclusion}

The $R$. nasatus leaf extract reduced $\mathrm{Ag}^{+}$metal ions and led to the formation of AgNps with fairly well-defined dimensions. This "green chemistry" approach for the synthesis of AgNps has many advantages, such as the ease with which the process can be scaled up and its economic viability. Applications for these eco-friendly nanoparticles in bactericidal, wound healing, and other medical and electronic applications signifies that this method has the potential for the large-scale synthesis of other inorganic nanomaterials. The antimicrobial screening demonstrated that the synthesized AgNps had a high inhibitory effect on bacteria. These observations may serve as a guide for studying the controlled release of these synthesized AgNps, which has potential in the field of infectious diseases. These AgNps may be explored as an option for decreasing the pathogenic potential of infectious bacterial and fungal species.

\section{Disclosure}

The authors report no conflicts of interest in this work.

\section{References}

1. Dubey SP, Lahtinen M, Sillanpää M. Tansy fruit mediated greener synthesis of silver and gold nanoparticles. Process Biochemistry. 2010;45(7):1065-1071.

2. Mukherjee P, Ahmad A, Mandal D, et al. Fungus-mediated synthesis of silver nanoparticles and their immobilization in the mycelial matrix: a novel biological approach to nanoparticle synthesis. Nano Letters. 2001;1(10):515-519.

3. Catauro M, Raucci M, De Gaetano F, Marotta A. Antibacterial and bioactive silver-containing $\mathrm{Na} 2 \mathrm{O} \cdot \mathrm{CaO} \cdot 2 \mathrm{SiO} 2$ glass prepared by solgel method. J Mater Sci Mater Med. 2004;15(7):831-837.

4. Singh A, Jain D, Upadhyay M, Khandelwal N, Verma H. Green synthesis of silver nanoparticles using Argemone Mexicana leaf extract and evaluation of their antimicrobial activities. Dig J Nanomater Bios 2010;5(2):483-489.

5. Balantrapu K, Goia D. Silver nanoparticles for printable electronics and biological applications. J Mater Res. 2009;24(9):2828-2836.

6. Tripathi R, Saxena A, Gupta N, Kapoor H, Singh R. High antibacterial activity of silver nanoballs against E. coli MTCC 1302, S. typhimurium MTCC 1254, B. subtilis MTCC 1133 and P. aeruginosa MTCC 2295. Dig J Nanomater Bios. 2010;5(2):323-330.

7. Starowicz M, Stypuła B, Banaś J. Electrochemical synthesis of silver nanoparticles. Electrochem Commun. 2006;8(2):227-230.

8. Sreeram K, Nidhin M, Nair B. Microwave assisted template synthesis of silver nanoparticles. Bulletin of Materials Science. 2008;31(7): 937-942.

9. Begum NA, Mondal S, Basu S, Laskar RA, Mandal D. Biogenic synthesis of $\mathrm{Au}$ and $\mathrm{Ag}$ nanoparticles using aqueous solutions of black tea leaf extracts. Colloids Surf B Biointerfaces. 2009;71(1): 113-118.

10. Lengke M, Southam G. Bioaccumulation of gold by sulfate-reducing bacteria cultured in the presence of gold (I)-thiosulfate complex. Geochim Cosmochim Acta . 2006;70(14):3646-3661.

11. Bhainsa KC, D'Souza S. Extracellular biosynthesis of silver nanoparticles using the fungus Aspergillus fumigatus. Colloids Surf B Biointerfaces. 2006;47(2):160-164.
12. Shankar SS, Rai A, Ahmad A, Sastry M. Rapid synthesis of Au, Ag, and bimetallic Au core-Ag shell nanoparticles using Neem (Azadirachta indica) leaf broth. J Colloid Interface Sci. 2004;275(2):496-502.

13. Arunachalam KD, Annamalai S, Hari S. One-step green synthesis and characterization of leaf extract-mediated biocompatible silver and gold nanoparticles from Memecylon umbellatum. Int J Nanomedicine. 2013;8:1307-1315.

14. Santhoshkumar T, Rahuman AA, Rajakumar G, et al. Synthesis of silver nanoparticles using Nelumbo nucifera leaf extract and its larvicidal activity against malaria and filariasis vectors. Parasitol Res. 2011;108(3):693-702.

15. Hebbalalu D, Lalley J, Nadagouda MN, Varma RS. Greener Techniques for the Synthesis of Silver Nanoparticles using Plant Extracts, Enzymes, Bacteria, Biodegradable Polymers and Microwaves. ACS Sustainable Chem Eng. 2013;1(7):703-712.

16. Moulton MC, Braydich-Stolle LK, Nadagouda MN, Kunzelman S, Hussain SM, Varma RS. Synthesis, characterization and biocompatibility of "green" synthesized silver nanoparticles using tea polyphenols. Nanoscale. 2010;2(5):763-770.

17. Kumar V, Yadav SK. Plant-mediated synthesis of silver and gold nanoparticles and their applications. J Chem Technol Biotechnol. 2009;84(2):151-157.

18. Jain D, Daima HK, Kachhwaha S, Kothari S. Synthesis of plant-mediated silver nanoparticles using papaya fruit extract and evaluation of their anti microbial activities. Dig J Nanomater Bios. 2009;4(3):557-563.

19. Lok CN, Ho CM, Chen R, et al. Silver nanoparticles: partial oxidation and antibacterial activities. J Biol Inorg Chem. 2007;12(4):527-534.

20. Shameli K, Ahmad MB, Zamanian A, et al. Green biosynthesis of silver nanoparticles using Curcuma longa tuber powder. Int J Nanomedicine. 2012; 7:5603-5610.

21. Ip M, Lui SL, Poon VK, Lung I, Burd A. Antimicrobial activities of silver dressings: an in vitro comparison. J Med Microbiol. 2006;55(Pt 1):59-63.

22. Jayaseelan C, Rahuman AA, Rajakumar G, Santhoshkumar T, Kirthi AV, Marimuthu S, Bagavan A, Kamaraj C, Zahir AA, Elango G. Efficacy of plant-mediated synthesized silver nanoparticles against hematophagous parasites. Parasitology research. 2012;111:921-933.

23. Valli JS, Vaseeharan B. Biosynthesis of silver nanoparticles by Cissus quadrangularis extracts. Materials Letters 2012;82:171-173.

24. Santhoshkumar T, Rahuman AA, Bagavan A, et al. Evaluation of stem aqueous extract and synthesized silver nanoparticles using Cissus quadrangularis against Hippobosca maculata and Rhipicephalus (Boophilus) microplus. Exp Parasitol. 2012;132(2):156-165.

25. Panáček A, Kolář M, Večeřová R, et al. Antifungal activity of silver nanoparticles against Candida spp. Biomaterials. 2009;30(31): 6333-6340.

26. Sathishkumar M, Sneha K, Won S, Cho CW, Kim S, Yun YS. Cinnamon zeylanicum bark extract and powder mediated green synthesis of nanocrystalline silver particles and its bactericidal activity. Colloids Surf B Biointerfaces. 2009;73(2):332-338.

27. Rogers JV, Parkinson CV, Choi YW, Speshock JL, Hussain SM. A preliminary assessment of silver nanoparticle inhibition of monkeypox virus plaque formation. Nanoscale Res Lett. 2008;3(4):129-133.

28. Rao PV, Goudu AS, Sasikala S, Naidu MD. Efficacy of antimicrobial activity of rhinacanthus nasutus (LINN) leaves in different extractions. Int J Pharma Bio Sci. 2010;1(2):1-4.

29. Tewtrakul S, Tansakul P, Panichayupakaranant P. Anti-allergic principles of Rhinacanthus nasutus leaves. Phytomedicine. 2009;16(10): 929-934.

30. Rao VP, Madhavi K, Naidu DM, Gan SH. Rhinacanthus nasutus Ameliorates Cytosolic and Mitochondrial Enzyme Levels in Streptozotocin-Induced Diabetic Rats. Evid Based Complementary Altern Med. 2013;2013:6.

31. Rao PV, Madhavi K, Naidu MD. Hypolipidemic properties of Rhinacanthus nasutus in streptozotocin induced diabetic rats. J Pharmacol Toxicol. 2011;6(6):589-595. 
32. Rao PV, Sujana P, Vijayakanth T, Naidu MD. Rhinacanthus nasutus-Its protective role in oxidative stress and antioxidant status in streptozotocin induced diabetic rats. Asian Pacific Journal of Tropical Disease. 2012;2(4):327-330.

33. Panghal M, Kaushal V, Yadav JP. In vitro antimicrobial activity of ten medicinal plants against clinical isolates of oral cancer cases. Ann Clin Microbiol Antimicrob. 2011;10:21.

34. Krishnaraj C, Jagan E, Rajasekar S, Selvakumar P, Kalaichelvan P, Mohan N. Synthesis of silver nanoparticles using Acalypha indica leaf extracts and its antibacterial activity against water borne pathogens. Colloids Surf B Biointerfaces. 2010;76(1):50-56.
35. Noginov M, Zhu G, Bahoura M, et al. The effect of gain and absorption on surface plasmons in metal nanoparticles. Appl Phys B. 2007;86(3): 455-460.

36. Ramanathan R, O’Mullane AP, Parikh RY, Smooker PM, Bhargava SK, Bansal V. Bacterial kinetics-controlled shape-directed biosynthesis of silver nanoplates using Morganella psychrotolerans. Langmuir. 2010;27(2):714-719.

37. Bansal V, Li V, O’Mullane AP, Bhargava SK. Shape dependent electrocatalytic behaviour of silver nanoparticles. CrystEngComm. 2010;12(12):4280-4286. 


\section{Supplementary materials}

\section{Measurement results}

Figure SI Zeta potential micrograph of silver nanoparticles synthesized using R.nasutus leaf extract. Measurement results

Date

Measurement type

Sample name

Temperature of the holder

: Sunday, Junuary 27, 2013 5:26:22 PM

Viscosity of the dispersion medium

: Zeta potential

Conductivity

7

Electrode voltage

$: 25.0^{\circ} \mathrm{C}$

: $0.894 \mathrm{mPa} \cdot \mathrm{s}$

: $0.260 \mathrm{mS} / \mathrm{cm}$

$: 3.3 \mathrm{~V}$

Calculation results

\begin{tabular}{|c|c|c|}
\hline Peak Number & Zeta potential & Electrophoretic mobility \\
\hline 1 & $-18.1 \mathrm{mV}$ & $-0.000140 \mathrm{~cm} 2 / \mathrm{Vs}$ \\
\hline 2 & $-\mathrm{mV}$ & $-\mathrm{cm} 2 / \mathrm{Vs}$ \\
\hline 3 & $-\mathrm{mV}$ & $-\mathrm{cm} 2 / \mathrm{Vs}$ \\
\hline
\end{tabular}

Zeta potential (mean) : $-18.1 \mathrm{mV}$

Electrophoretic mobility mean $\quad:-0.000140 \mathrm{~cm}^{2} / \mathrm{Vs}$

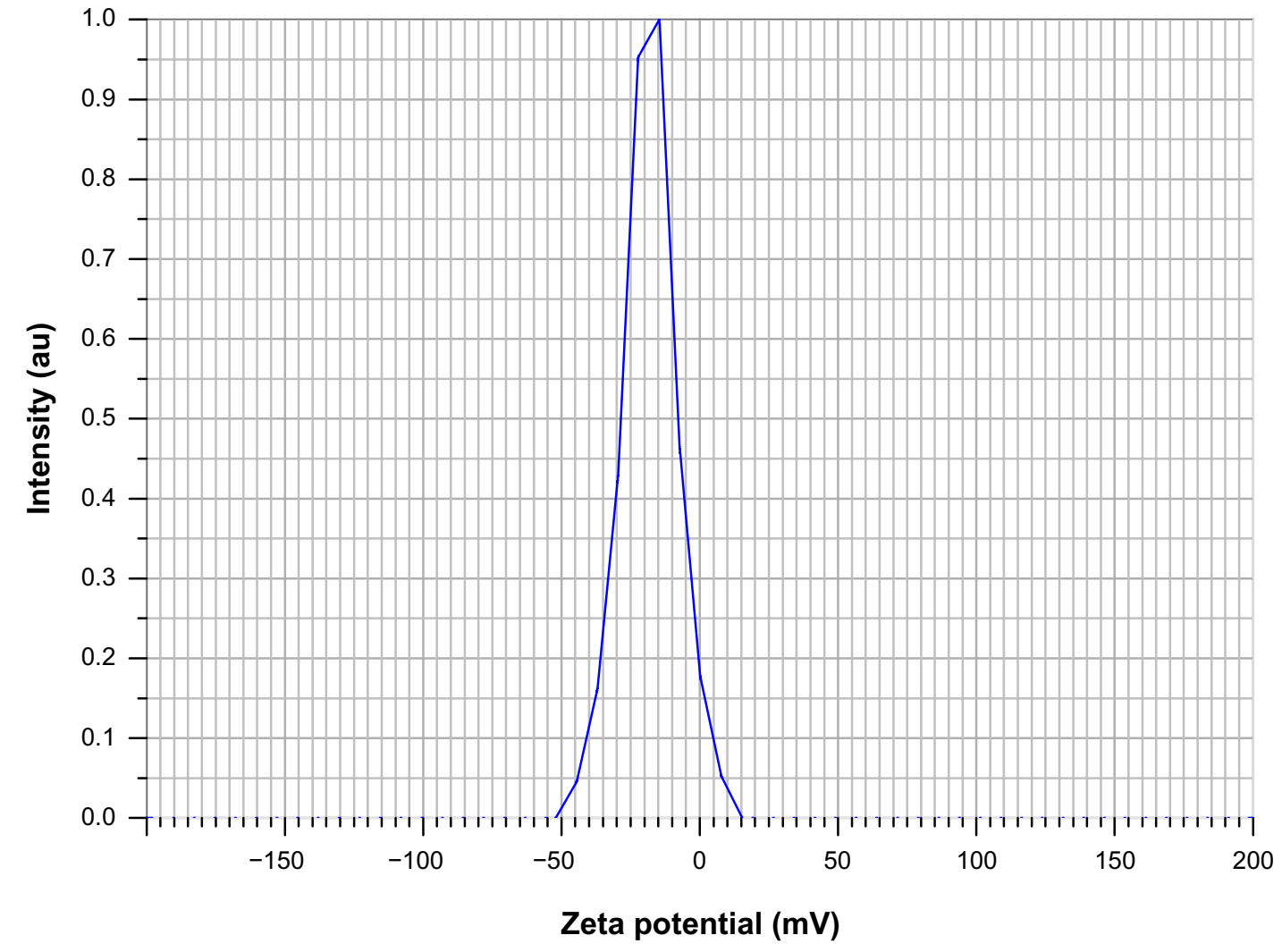


Figure S2 Particle size distribution of silver nanoparticles synthesized using R.nasutus leaf extract.

\section{Measurement results}

\section{Date}

Measurement type

Sample name

Scattering angle

Temperature of the holder

Transmission percent (T\%) before measure

Viscosity of the dispersion medium

Form of distribution

Representation of result

Count rate
: Sunday, January 27, 2013 6:20:49 PM

: Particle size

$: 7$

$: 173$

: $25.0^{\circ} \mathrm{C}$

$: 1715$

: $0.894 \mathrm{mPas}$

: Standard

: Scattering light intensity

: 1355 kCPS

\section{Calculation results}

\begin{tabular}{|c|c|c|c|c|}
\hline Peak Number & Specific surface area ratio & Mean & Standard deviation & \\
\hline 1 & 1.00 & $538.6 \mathrm{~nm}$ & $427.8 \mathrm{~nm}$ & $335.4 \mathrm{~nm}$ \\
\hline 2 & - & $-\mathrm{nm}$ & $-\mathrm{nm}$ & $-\mathrm{nm}$ \\
\hline 3 & - & $-\mathrm{nm}$ & $-\mathrm{nm}$ & $-\mathrm{nm}$ \\
\hline Total & 1.00 & $538.6 \mathrm{~nm}$ & $427.8 \mathrm{~nm}$ & $335.4 \mathrm{~nm}$ \\
\hline
\end{tabular}

\section{Cumulant operations}

\section{Z-average}

Polydispersity index

\section{Molecular weight measurement}

Molecular weight

Mark-Houwink-Sakurada parameters

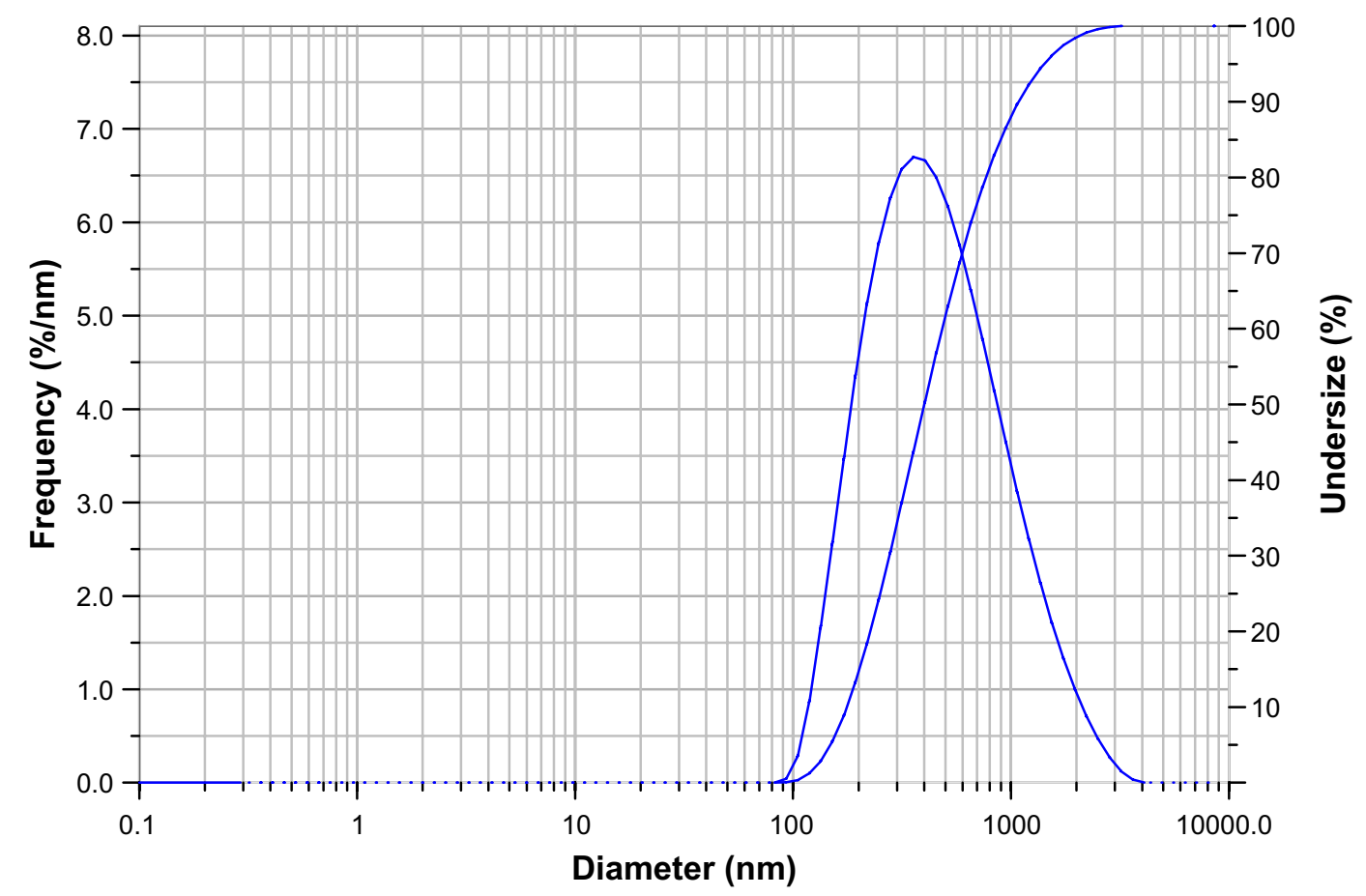

International Journal of Nanomedicine

\section{Publish your work in this journal}

The International Journal of Nanomedicine is an international, peerreviewed journal focusing on the application of nanotechnology in diagnostics, therapeutics, and drug delivery systems throughout the biomedical field. This journal is indexed on PubMed Central, MedLine, CAS, SciSearch $\AA$, Current Contents ${ }^{\circledR} /$ Clinical Medicine,
Journal Citation Reports/Science Edition, EMBase, Scopus and the Elsevier Bibliographic databases. The manuscript management system is completely online and includes a very quick and fair peer-review system, which is all easy to use. Visit http://www.dovepress.com/ testimonials.php to read real quotes from published authors. 